УДК 930(47+57)"19”(045)

\title{
И.Н. Вельможко
}

\section{К ВОПРОСУ О МЕТОДОЛОГИЧЕСКИХ АСПЕКТАХ ИСТОРИОГРАФИИ 1990-Х ГОДОВ (НА ПРИМЕРЕ ПУБЛИКАЦИЙ О «ХРУЩЁВСКОЙ ОТТЕПЕЛИ»)}

Статья посвящена исследованию методологических аспектов историографии такого сложного для отечественной исторической науки периода, как 1990-е гг. Изменения, которые произошли в нашей стране в последнее десятилетие XX в., оказали влияние на все сферы жизни, в том числе и на отечественную историческую науку, в которой перестали доминировать принципы марксистко-ленинской идеологии. Для отечественной исторической науки 1990-е гг. стали временем формирования новых методологических приоритетов, поиска научных основ, общих законов развития общества. Несмотря на все сложности одним из наиболее разрабатываемых периодов отечественной истории в данное время стали 50-60-е гг. XX в. - время, за которыми в исторической науке прочно закрепилось определение «хрущёвская оттепель». На примере публикаций о «хрущёвской оттепели» в статье проанализированы основные тенденции, характерные для историографии 1990-х гг., показаны их методологические особенности, попытки поиска российскими историками новых концепций интерпретации советского периода отечественной истории.

Ключевые слова: идеология, историческая наука, историография, литература, «оттепель», проблематика, теория общественно-экономических формаций, цивилизационная методология.

DOI: $10.35634 / 2412-9534-2020-30-4-668-673$

Структурные изменения, произошедшие в нашей стране в 1990-е гг., проявились не только в экономической и политической сферах, но и самым радикальным образом повлияли на историческую науку. Этот период стал временем поиска новых методологических основ отечественной исторической науки, переосмысления составных элементов системы научного знания, поиска новых концепций интерпретации истории. Хотя историческая наука не стоит на месте, в научный оборот вводятся целые пласты исторических источников, в поле зрения историков попадают новые темы, уже апробированные направления исследований часто предстают в новых трактовках. Тем не менее, исследование методологических аспектов не утратило своей значимости.

В советское время в отечественной историографии доминировало унифицированное понимание исторического процесса на основе марксистко-ленинской идеологии. В 1990-е гг. марксистколенинские идеологические постулаты, принципы классовости и партийности в исторической науке утратили приоритетность, наметились тенденции обновления методологических подходов к изучению истории. Перед отечественными исследователями обозначилась проблема поиска новых научных основ, общих законов развития, более совершенных, чем теория общественно-экономических формаций. Происходила переоценка ценностей. Появились работы, в которых состояние отечественной историографии определялось как кризисное [8]. В условиях, когда требовалось найти альтернативу марксизму, возник интерес к цивилизационной методологии.

Интересна в этом плане работа Л. И. Семенниковой «Россия в мировом сообществе цивилизаций» (1996). Хотя периоду «оттепели» в ней уделено ограниченное место, тем не менее, рассмотрение истории России как результата взаимодействия с другими государствами, одного из элементов развития истории всей цивилизации способствовало расширению методологических параметров изучения исторического процесса.

В конце XX в. характерной особенностью исторических исследований становится активное использование историко-системного метода, который предполагает целостный охват истории, события, явления рассматриваются в развитии. Но методологические проблемы, главным образом, рассматривались в публикациях философской направленности. Причём философы разрабатывали проблематику не только философии истории, но и, используя в основном уже введённый в научный оборот исторический материал, истории как таковой [10-12].

Тем не менее, историческая наука не стояла на месте, велись дискуссии на самые разнообразные темы, публиковались статьи. Активно разрабатываемым сегментом историографии 1990-х гг. стало первое послесталинское десятилетие, за которым в исторической науке прочно закрепилось определение «хрущёвская оттепель», усилился интерес к личности Н. С. Хрущёва. Многие темы ста- 
ли открытыми для исследователей. Появились публикации с ярко выраженным методологическим посылом, в которых предпринимались попытки концептуальной оценки деятельности Н. С. Хрущёва и его «великого десятилетия».

В свет начали выходить работы, освещающие не только личность Хрущёва, но и ранее замалчиваемые факты его деятельности. Так, А. Н. Пономарёв, подытожив исследования прежних лет, издал брошюру «Н. С. Хрущёв: путь к лидерству» (1990). Следует признать, что эта работа является беспрецедентной, так как в исследовании московского периода опыт политического руководства представлен как важная веха в карьере Н. С. Хрущёва. Благодаря А. Н. Пономарёву в научный оборот были введены многие неизвестные ранее архивные документы, поставлена новая проблема в изучении процессов 1930-х гг. и биографии Н. С. Хрущёва. Однако отметим, что А. Н. Пономарёв, освещая партийно-политическую деятельность Н. С. Хрущёва в Москве, отдаёт предпочтение стенограммам его выступлений. Не всегда связывая заявления и поступки Н. С. Хрущёва с политикой И. В. Сталина, историк оставляет мотивы некоторых из них не раскрытыми, слабо обозначена связь с политикой, проводимой Н. С. Хрущёвым в послесталинский период.

В разноплановых публикациях, посвящённых «оттепели» внимание историков привлекали, прежде всего, политические процессы, которые происходили в нашей стране в 50-60-гг. XX в. Заметной работой историко-политической направленности стала книга «XX съезд и его исторические реальности» (1991). На основе анализа обширного фактологического материала авторским коллективом бывшего Института марксизма-ленинизма под руководством Н. А. Барсукова была предпринята попытка нового переосмысления реформационной практики 50-60-х гг. XX в.

Импульсом к усилению общественного внимания к исторической проблематике середины прошлого века стал 100-летний юбилей со дня рождения Н. С. Хрущёва (апрель 1994 г.) [7]. В книге Д. А. Волкогонова «Семь вождей» (1996) одна из глав посвящена Н. С. Хрущёву. Опираясь на уникальные документы, прежде всего из Архива Президента Российской Федерации, автор проанализировал обстоятельства прихода Н. С. Хрущёва к власти, борьбу за лидерство в партии и другие события политической жизни страны середины XX в. Несмотря на разность подходов и оценок, характерной особенностью названных публикаций была их историко-политологическая направленность с неизбежным в этом случае преобладаем интереса к высшим политическим сферам, судьбе лидеров.

Новым явлением в развитии исторической мысли конца XX в. стало появление большого количества переводной литературы, посвящённой изучению советской истории. В 1990 г. вышла двухтомная монография Дж. Боффа «История Советского Союза», а в 1992 г. - книга Н. Верта «История советского государства. 1900-1991», в которых событиям послесталинского периода уделено значительное внимание.

Одной из важнейших проблем России всегда было развитие аграрного сектора. В 1990-е гг. история крестьянства разрабатывалась достаточно интенсивно, предпринимались попытки переосмысления аграрной политики, в том числе и в середине XX в. Первенство в исследовании аграрной политики и развития сельского хозяйства в 1953-1964 гг. принадлежит известному экономисту-аграрнику О. М. Вербицкой. Её монография, посвящённая крестьянству России, стала одной из первых обобщающих работ [5]. Публикация новых архивных источников, в том числе сводных годовых отчётов колхозов, бюджетных обследований крестьянских семей, демографической статистики, позволило автору дать объективную и достаточно полную характеристику социально-демографических изменений в деревне, материально-бытового положения крестьянства на первом этапе хрущёвских реформ.

Особое место в историографии аграрной темы занимают работы, посвящённые российскому Нечерноземью, «неперспективной» (исчезающей) деревне [3; 9]. Авторов интересуют, главным образом, социально-экономические и демографические изменения в деревне. На основе анализа партийных документов делается вывод, что социальная политика, проводимая КПСС, вступала в противоречие с официальным курсом на повышение уровня жизни советских людей. Несмотря на рост капиталовложений в непроизводственное строительство, не были решены многие вопросы культурнобытового и медицинского обслуживания сельских жителей. Это приводило к оттоку молодёжи и специалистов в города и негативно сказывалось на развитии сельскохозяйственного производства.

В 1998 г. вышел в свет 4 том «Истории советского крестьянства», охватывающий первые послевоенные годы и период до конца 1950-х гг. Ценные, нередко впервые вводимые в оборот фактические данные весьма обогатили историографию, однако концептуальные подходы остались в основном прежние. Хронологическое завершение тома концом 1950-х гг. не позволило авторам довести до логического завершения исследование хрущёвских реформ. 
В 1990-е гг. историческая наука значительно обогатилась исследованиями по социальной истории, исторической психологии, истории менталитета и общественного сознания. Во многом это связано со стремлением преодолеть традиционный подход, согласно которому социально-экономическая и общественная жизнь страны освещалась лишь с официальных позиций. Интерес к жизни и мнению так наз. «простого человека» базируется на почве самоисчерпания позитивистских приёмов работы с источниками и устаревания прежних объяснительных парадигм. Научные интересы исследователей переместились с макроуровня на микроуровень, уровень событийный, локальный. Достаточно продолжительное время он оставался за пределами внимания историков.

Первому послесталинскому десятилетию посвящено несколько монографических исследований. Заметным явлением в историографии стали работы Е. Ю.Зубковой «Общество и реформы. 19451964» (1993), «От 60-х к 70-м: власть, общество, человек» (1991).

Анализу социально-психологических аспектов общественной жизни страны посвящено исследование Б. А. Грушина «Четыре жизни России. Жизнь 1. Эпоха Хрущёва» (1999). На базе свыше 250 эмпирических разработок предпринята не имеющая аналогов попытка смоделировать, в том числе в динамике, некоторые значимые свойства менталитета российского народа. В книге первой, об эпохе Хрущёва, подобного рода анализ проводится на материалах опросов населения Институтом общественного мнения газеты «Комсомольская правда» в 1960-1964 гг. Публикация выявляет неадекватность намерений властей и их восприятия обществом. Наряду с этим воссоздаётся атмосфера, эмоциональный настрой эпохи.

Исследованию эволюции взаимоотношений власти и представителей культуры посвящена книга М. Р. Зезиной «Советская художественная интеллигенция и власть в 50-е - 60-е годы» (1999). Автор рассматривает различные подходы к определению понятия «интеллигенция», характеризует художественную интеллигенцию СССР в начале 1950-х гг., анализирует динамику изменения её численности по переписи 1959 г.

Система партийного руководства литературой и искусством, ставившая под контроль творчество талантливых людей, заставляя их выполнять идеологические задачи, по мнению автора, являлась главной причиной кризисных явлений в культурной сфере. В книге рассмотрена ситуация, возникшая вокруг журнала «Новый мир» с писателями А. Ахматовой, М. Зощенко, Б. Пастернаком, В. Гроссманом и др. Автор считает, что главным и наиболее острым вопросом, разделявшим художественную интеллигенцию, была проблема сталинизма. Переосмысление роли интеллигенции представлено в контексте общей культурной политики.

Существенный вклад в понимание особенностей развития советского общества вносят специалисты, занимающиеся историей «холодной войны» и международных отношений, которые по-своему влияли на жизнь внутри страны [14; 15; 17].

В 1990-е гг. библиография отечественной истории была расширена за счёт тем, которые ранее не исследовались советскими историками. Следует отметить работу М. В. Шкаровского «Русская православная Церковь при Сталине и Хрущёве (государственно-церковные отношения в СССР в 1939-1964 годах)» (1999). В монографии исследуется предвоенное, военное и послевоенное время. Автор использовал широкий круг источников: фонды центральных партийных и государственных архивов, документы архивохранилищ Санкт-Петербурга. В книге анализируется положение официальной Православной церкви. Автор показывает «церковное подполье», обстоятельно описывает способы самовыражения «непримиримых». Бесспорным представляется вывод, что, вопреки строжайшему организационному контролю, государству не удалось установить тотальный надзор над религиозными убеждениями населения. Государственная политика предвоенного, военного и послевоенного периода была частью политической игры, где Церкви надлежало играть важную, но срежиссированную властью роль.

Монография компенсирует пробелы отечественной историографии в области церковной политики советского государства.

Дискуссионные проблемы советской действительности 50-60-х гг. ХХ в. нашли отражение в мемуарной литературе. Воспоминания непосредственных участников событий предоставляют возможность зримо воссоздать атмосферу, эмоциональный настрой эпохи, позволяют почувствовать её жизненную повседневность.

Интересный материал для историко-психологического анализа содержится в воспоминаниях самого Н. С. Хрущёва, впервые изданных в 1982 г. и переизданных в 1990-ом. 
Смена методологических приоритетов в историографии отразилась даже на мемуарной литературе. В начале 1990-х гг. стали выходить из печати мемуары «семейного круга», то есть членов семей советских руководителей: А. И. Аджубея, А. Г. Маленкова, С. Н. Хрущёва, предлагающие довольно своеобразный взгляд на историю и роль того или иного политика $[1 ; 13 ; 18]$.

Отрывочные свидетельства людей, работавших в разное время вместе с Н. С. Хрущёвым, дополняют коллективный психологический портрет высшего руководства страны [6]. Исключение составляет сборник бесед с В. М. Молотовым, имя которого связано с целой исторической эпохой и чьи взгляды во многих чертах отражают мышление той эпохи [10].

По-иному представлена история реформ в воспоминаниях людей, которые не принадлежали к ближайшему окружению высшего руководства, но работали непосредственно с ним. Первыми в этой группе мемуарной литературы появились книги Г. А. Арбатова и Ф. М. Бурлацкого [2; 4]. Свидетельства очевидца корректируются взглядом аналитика, и картина времени, таким образом, получает известную законченность, хотя вопрос о принципах отбора фактов и в этом случае остаётся открытым.

Если мемуары политиков и их окружения представляют жизнь высших сфер, то более широкие общественные процессы отразились в другом круге мемуарной литературы - в мемуарах литераторов-писателей, поэтов, журналистов. Воспоминания и дневники Ф. А. Абрамова, Э. Г. Казакевича, В. Я. Лакшина, В. В. Овечкина, А. Т. Твардовского, К. М. Симонова, К. И. Чуковского, И. Г. Эренбурга и др. - это рассказ не только о литературной жизни 50-60-х гг. ХХ в., но и рассуждения об общих проблемах истории страны, о зарождении в обществе новых тенденций и явлений, которые станут символами «оттепели».

Для познания исторической картины мира наука должна опираться на методологию, которая определяет понятийные принципы, общие методы получения знаний о прошлом. В 90-е гг. ХХ в. марксистско-ленинские идеологические постулаты, принципы классовости и партийности утратили приоритетность, произошло обновление методологических подходов к изучению истории, расширился диапазон рассматриваемых проблем.

Различные аспекты структурных изменений советского государства и общества в середине XX в. получили неоднозначное, подчас противоречивое отображение в научных трудах, публицистике, литературе и искусстве. Неоднозначно рассматриваются и оцениваются они и в историографии. В 1990-е гг. российские историки стремились пересмотреть исторический путь страны. Постепенно сформировалось понимание интегрированности советской истории в историю российскую и общемировую.

Интенсивная разработка темы послесталинского десятилетия в истории страны вызвана необходимостью, даже насущной потребностью в обобщающих трудах, способных системно охарактеризовать и масштабы, и пределы процессов либерализации советской действительности в 50-60 гг. $\mathrm{XX}$ в. Углубляя и развивая, концептуализируя собственные исследовательские наработки, продуктивно используя отечественную и зарубежную историографию, вводя в оборот целые пласты малоизвестных и совсем неизвестных науке источников, историки создали труды, которые можно оценить как этапные в плане осмысления нашей исторической наукой места и роли «хрущёвского десятилетия» в исторических судьбах Отечества.

\section{СПИСОК ИСТОЧНИКОВ И ЛИТЕРАТУРЫ}

1. Аджубей А. И. Те десять лет. М.: Советская Россия, 1989. 336 с.

2. Арбатов Г. А. Затянувшееся выздоровление. 1953-1985. Свидетельство современника. М.: Международные отношения, 1991. 402 с.

3. Безнин М. А. Крестьянский двор в Российском Нечерноземье 1950-1965 гг. Вологда: Вологодский пед. ин-т, $1991.255 \mathrm{c}$.

4. Бурлаикий Ф. М. Вожди и советники: о Хрущёве, Андропове и не только о них... М.: Политиздат, 1990.384 с.

5. Вербиикая О. М. Российское крестьянство: от Сталина к Хрущёву. Середина 40-х — начало 60-х годов. М.: Наука, 1992. 222 с

6. Воронов Г. И. Немного воспоминаний // От оттепели до застоя / сост. Г. В. Иванова. М.: Советская Россия, $1990.254 \mathrm{c}$.

7. Горбачёв М. С. Сильнее воли политиков // Материалы науч. конф., посвящ. 100-летию со дня рожд. Хрущёва Н.С., 18 апр. 1994. М.: РГГУ, 1994. 377 с.

8. Гуревич А. Я. О кризисе современной отечественной науки // Вопр. истории. 1991. № 2-3. С. $28-36$.

9. Денисова Л. Н. Исчезающая деревня России: Нечерноземье в 1960-1980-е годы. М.: Логос, 1996. 216 с.

10. Ильин В. В., Панарин А. С., Ахиезер А. С. Реформы и контрреформы в России. М.: Изд-во Моск. ун-та, 1996. $399 \mathrm{c}$. 
11. Ильин В. В., Ахиезер А. С. Российская государственность: истоки, традиции перспективы. М. Изд-во Моск. ун-та, 1997. $384 \mathrm{c.}$

12. Ильин B. В., Ахиезер A. C. Российская цивилизация: содержание, границы возможности. М. Изд-во Моск. унта, 2000. $301 \mathrm{c}$.

13. Маленков А. Г. О моём отце Георгии Маленкове. М.: Техноэкос, 1992. 116 с.

14. Советская внешняя политика в годы «холодной войны» (1945-1985). Новое прочтение. М.: Международные отношения, 1995. 508 с.

15. Сталин и холодная война. М.: ИВИ РАН, 1998. $366 \mathrm{c.}$

16. Сто бесед с В. М. Молотовым: Из дневника Ф. Чуева. М.: ТЕРРА, 1991. 623 с.

17. Холодная война. Новые подходы, новые документы. М: ИВИ РАН, 1995. 400 с.

18. Хрущёв С. Н. Пенсионер союзного значения. М.: Новости, 1991. 413 с.

Поступила в редакцию 18.01.2020

Вельможко Ирина Николаевна, кандидат исторических наук, доцент, зав. кафедрой истории ФГБОУ ВО «Московский авиационный институт (Национальный исследовательский университет)» 125993, Россия, г. Москва, А-80, ГСП-3, Волоколамское шоссе, 4 E-mail: kaf002-501@mai.ru

\title{
I.N. Velmozhko \\ ON THE ISSUE OF METHODOLOGICAL ASPECTS OF HISTORIOGRAPHY IN THE 1990S (ON THE EXAMPLE OF PUBLICATIONS ABOUT THE “KHRUSHCHEV THAW")
}

\author{
DOI: $10.35634 / 2412-9534-2020-30-4-668-673$
}

The article is devoted to the study of methodological aspects of historiography of such a difficult period for Russian historical science as the 1990s. The changes that have taken place in our country in the last decade of the twentieth century have had an impact on all spheres of life, including the Russian historical science, which has ceased to be dominated by the principles of Marxist-Leninist ideology. For Russian historical science, the 1990s were a time of forming new methodological priorities, searching for scientific foundations, and general laws for the development of society. Despite all the difficulties, one of the most developed periods of Russian history at this time were the 50-60s of the twentieth century, the time for which the definition of "Khrushchev Thaw" was firmly established in historical science. Using the example of publications about the "Khrushchev Thaw", the article analyzes the main trends characteristic of the historiography of the 1990s, shows their methodological features, and attempts to search for them by Russian historians

Keywords: ideology, historical science, historiography, literature, "thaw", problems, theory of socio-economic formations, civilizational methodology.

\section{REFERENCES}

1. Adzhubeya A. I. Te desyat' let [During the ten years]. Moscow, "Sovetskaya Rossiya" Publ., 1989, 336 p. (In Russian).

2. Arbatov G. A. Zatyanuvsheesya vy'zdorovlenie. 1953-1985. Svidetel'stvo sovremennika [Delayed recovery. 19531985. The testimony of a contemporary]. Moscow, "Mezhdunarodnye otnosheniya" Publ., 1991, 402 p. (In Russian).

3. Beznin M. A. Krest'yanskij dvor v Rossijskom Nechernozem'e. 1950-1965 gg. [The Peasant court in the Russian non-Chernozem region. 1950-1965]. Vologda, Vologda Pedagogical Institute Press, 1991, 255 p. (In Russian).

4. Burlaczkij F. M. Vozhdi i sovetniki: o Khrushheve, Andropove i ne tol'ko o nix... [Leaders and advisers: about Khrushchev, Andropov and not only about them...]. Moscow, "Politizdat" Publ., 1990, 384 p. (In Russian).

5. Verbiczkaya O. M. Rossijskoe krest'yanstvo: ot Stalina k Khrushhevu. Seredina 40-x — nachalo 60-x godov [Russian peasantry: from Stalin to Khrushchev. Mid-40s — early 60s]. Moscow, "Nauka" Publ., 1992, 222 p. (In Russian).

6. Voronov G. I. Nemnogo vospominanij. Ot ottepeli do zastoya. Sost. G. V. Ivanova [Some memories. From thaw to stagnation. Comp. by G. V. Ivanov]. Moscow, "Soviet Russia” Publ., 1990, 254 p. (In Russian).

7. Gorbachev M.S. Sil'nee voli politikov. Materialy nauchnoj konferencii, posvyashhennoj 100-letiyu so dnya rozhdeniya Khrushheva N. S. 18 aprelya 1994 [Stronger than the will of politicians. Materials of the scientific conference dedicated to the 100th anniversary of the birth of N. S. Khrushchev on April 18, 1994]. Moscow, RSUH Press, 1994, 377 p. (In Russian).

8. Gurevich A. Ya. O krizise sovremennoj otechestvennoj nauki [About the crisis of modern Russian science]. Voprosy istori [Question of History], 1991, no. 2-3, pp. 28-36. (In Russian)

9. Denisova L. N. Ischezayushhaya derevnya Rossii: Nechernozem'e v 1960-1980-e gody [The Disappearing village of Russia: The non-black earth region in 1960-1980-ies]. Moscow, “Logos” Publ., 1996, 216 p. (In Russian). 
10. Il'in V. V., Panarin A. S., Axiezer A. S. Reformy i kontrreformy v Rossii [Reform and counter-reform in Russia]. Moscow, Moscow State University Press, 1996, 399 p. (In Russian).

11. Il'in V. V., Axiezer A. S. Rossijskaya gosudarstvennost': istoki, tradicii perspektivy [Russian statehood: origins, traditions and prospects]. Moscow, Moscow State University Press, 1997, 384 p. (In Russian).

12. Il'in $V$. $V$., Axiezer $A$. S. Rossijskaya civilizaciya: soderzhanie, granicy vozmozhnosti [Russian civilization: content, borders of possibility]. Moscow, Moscow State University Press, 2000, 301 p. (In Russian)

13. Malenkov A. G. O moem otce Georgii Malenkove [About my father George Malenkov]. Moscow, "Technoekos" Publ., 1992, 116 p. (In Russian).

14. Sovetskaya vneshnyaya politika v gody "kholodnoj vojny" (1945-1985). Novoe prochtenie [Soviet foreign policy during the "cold war" (1945-1985). New reading]. Moscow, "International relations" Publ., 1995, 508 p. (In Russian).

15. Stalin i kholodnaya vojna [Stalin and the cold war]. Moscow, IGH of the RAS Press, 1998, 366 p. (In Russian).

16. Sto besed s V. M. Molotovym: Iz dnevnika F. Chueva [A hundred conversations with Molotov: From the diary of F. Chuev]. Moscow, “TERRA” Publ., 1991, 623 p. (In Russian).

17. Kholodnaya vojna. Novye podkhody, novye dokumenty [The cold war. New approaches, new documents]. Moscow, IGH of the RAS Press, 1995, 400 p. (In Russian).

18. Khrushhev S. N. Pensioner soyuznogo znacheniya [Pensioner of the Union value]. Moscow, "Novosti” Publ., 1991, 413 p. (In Russian).

Velmozhko I. N., Candidate of History, Associate Professor, Head of Department of History

Moscow Aviation Institute (National Research University)

Volokolamskoe shosse, 4, Moscow, A-80, GSP-3, Russia, 125993

E-mail: kaf002-501@mai.ru 